\title{
Emphasizing the link between blood types in multi-ethnic disparities and COVID-19 infection in Makkah, Saudi Arabia
}

Wesam A. Nasif, MSc, PhD, Abeer S.E. Ali, MBBCh, MSc, Asim A. Khogeer, MSc, PhD, Mohammed H. Mukhtar, MPhil, PhD, Mohamed M. NourEldein, MSc, PhD, Ahmed Y. Shebly, MBBCh, Shumukh H. Alqahtani, MBBCh, Yahya A. Alnashri, MBBCh, Ghaidaa E. Khouj, MBBCh, Ziyad I. Gadah, MBBCh, Mohammad A. Althubiti, MSc, PhD.

\begin{abstract}

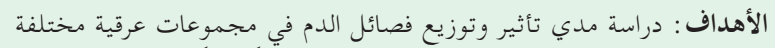

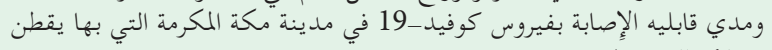
فيها أعراق مختلفة.

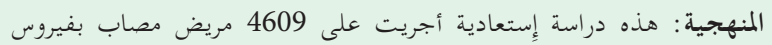

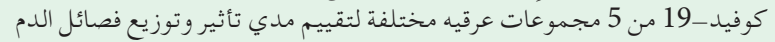

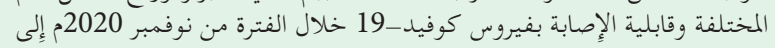

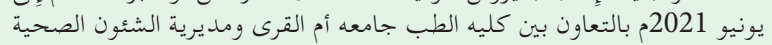

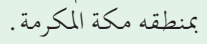

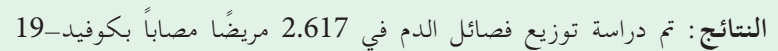

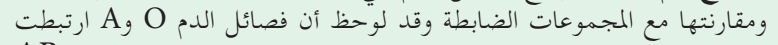

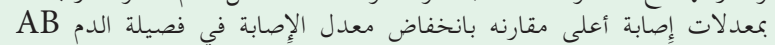

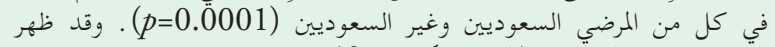

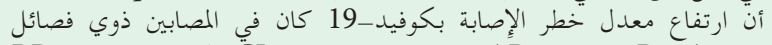

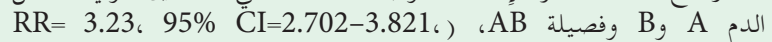
كان خطر الإصابة أقل لكوفيد-19 ( RR=0.783، 95\% CI=0.733-0.836،

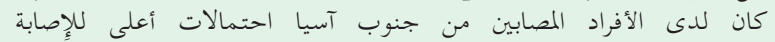

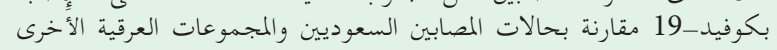
.(OR=1.12، 95\% CI: 1.074-1.24، $p=0.04$ )

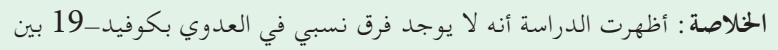

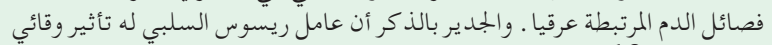

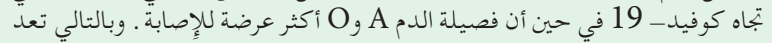

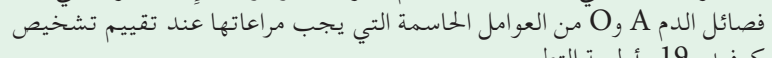

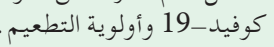

Objectives: To analyze the impact and distribution of blood groups in different ethnicities and the extent of susceptibility to infection with COVID-19 in Makkah, Saudi Arabia.

Methods: A retrospective study was performed on 4,609 COVID-19 patients from five ethnic groups to assess the impact and distribution of different blood types and susceptibility to COVID-19 infection. The study was carried out between November 2020 and June 2021 in the College of Medicine, Umm Al-Qura University in collaboration with the General Directorate of Health Affairs, Makkah, Saudi Arabia.
Results: Blood group (A, B, and $\mathrm{O}$ ) distributions in 2,617 COVID-19 patients with local control populations was done. Our study found that in both Saudi and non-Saudi populations, blood groups $\mathrm{O}$ and A were associated with higher infection rates, whereas blood group $\mathrm{AB}$ was associated with lower infection rates $(p=0.0001)$. COVID-19 seems to be associated with blood groups $\mathrm{A}, \mathrm{B}$, and $\mathrm{AB}(\mathrm{RR}=3.23,95 \% \mathrm{CI}=2.702$ $3.821, p=0.0001)$. COVID-19 risk was lower in people with O blood group ( $\mathrm{RR}=0.783,95 \% \mathrm{CI}=0.733-0.836$, $p=0.0001$ ). South Asians had higher odds of COVID-19 infection when compared to Saudi cases and other ethnic groups (OR=1.12, $95 \% \mathrm{CI}$ : 1.074-1.24, $p=0.04)$.

Conclusion: We emphasize that COVID-19 infection is not proportional among ethnically related blood groups. Notably, RhD-negative protect against COVID-19, whereas $\mathrm{A}$ and $\mathrm{O}$ blood types are more susceptible. Thus, when assessing COVID-19 prognosis and vaccination priority, blood groups $\mathrm{A}$ and $\mathrm{O}$ are critical.

Keywords: ABO blood group, RhD, COVID-19, ethnicity, risk, prevalence

Saudi Med J 2022; Vol. 43 (2): 177-186

doi: 10.15537/smj.2022.43.2.20210847

From Biochemistry Department (Nasif, Mukhtar, Nour Eldein, Althubiti), From Pathology Department (Ali), from the College of Medicine (Alqahtani, Alnashri, Khouj, Gadah), Umm Al-Qura University; From Plan and Research Department (Khogeer), General Directorate of Health Affairs Makkah Region, Ministry of Health; From Ajyad Emergency Hospital (Shebly), Ministry of Health, Makkah, Kingdom of Saudi Arabia.

Received 19th October 2021. Accepted 26th December 2021.

Address correspondence and reprint request to: $D r$. Wesam A. Nasif, Professor of Biochemistry, Faculty of Medicine, Umm Al-Qura University, Makkah, Kingdom of Saudi Arabia. E-mail:wnasif2003@yahoo.com

ORCID ID: https://orcid.org/0000-0002-5119-0137 
$\mathrm{C}$ OVID-19 is caused by the novel SARS-CoV-2 coronavirus; following initial infections in Wuhan, Hubei province, China, it has spread to nearly every country in the world, leading to a substantial number of deaths and an increasing economic burden. ${ }^{1}$ The World Health Organization (WHO) declared the novel coronavirus (COVID-19) outbreak a global pandemic on March 11, 2020. ${ }^{2}$ By 9 December 2021, the World Health Organization (WHO) announced that the number of cases worldwide had reached $269,112,118$ infected cases worldwide with a total of 550,136 reported cases in Saudi Arabia as daily reports and a total of 5,307,847deaths globally. ${ }^{3}$ The Kingdom of Saudi Arabia (KSA) is unique in that it serves as a hub for millions of international employees and pilgrims from all over the world. In early March 2020, the first case of COVID-19 was confirmed in the Kingdom of Saudi Arabia, and since then, it has caused thousands of deaths. ${ }^{4}$ Patients with COVID-19 mostly present with symptoms including fatigue, fever and dry cough, followed by myalgia, anorexia, dyspnea, and more. ${ }^{5}$ However, some patients quickly develop acute respiratory distress syndrome, shock, acidosis and coagulopathy, which can be fatal. ${ }^{5}$ Multilabel factors including age, gender, comorbidities, economic status, and genetic makeup of the subject contribute to COVID-19 infection. ${ }^{1}$ The virus's morphology is similar to that of other coronaviruses, most notably SARS-CoV and MERS-CoV. ${ }^{7,8}$ The receptor on the target cell is critical in determining how the virus enters the cell and which tissues are infected. The spike glycoproteins interact with the viral envelope and the cytomembrane of the target cell. One recent study indicated that the COVID-19 cell receptor is predicted to be angiotensinconverting enzyme 2 (ACE2). ${ }^{1}$

It is well known that individuals with particular $\mathrm{ABO}$ blood groups are at an increased risk of contracting several types of infections.' Following the outbreak of COVID-19, researchers studied the potential of a link between $\mathrm{ABO}$ blood types and susceptibility to COVID-19 exposure. The researchers, however, recommended more studies be conducted to validate the link between ABO blood grouping and COVID-19 infection. ${ }^{10}$ The $\mathrm{ABO}$ blood group is an antigen that is expressed in red blood cells and a variety of other cell lines and tissues. $\mathrm{N}$-acetyl galactosamine is a sugar that

Disclosure. Authors have no conflict of interests, and the work was not supported or funded by any drug company. instructs the blood groups; coronaviruses have surface proteins that tend to adhere to sugars. However, this sugar is missing on $\mathrm{O}$ blood group cells. ${ }^{11}$ Moreover, there have been suggestions regarding the association of the SARS-CoV-2 spike (S) protein with the ACE2 protein that acts as its cellular receptor. However, the presence of an anti-A antibody may inhibit the adherence of the spike protein to the ACE2 receptor on the host cell surface. ${ }^{12}$

Therefore, several studies have discussed the association of $\mathrm{ABO}$ blood grouping and host susceptibility to infectious diseases such as Severe Acute Respiratory Syndrome, symptomatic West Nile Virus, Human Immunodeficiency Virus (HIV), Hepatitis B, Norwalk virus1, Helicobacter pylori, and Plasmodium falciparum. ${ }^{11,13}$ Previous studies have found that this association is because $\mathrm{ABO}$ antibodies are a component of the innate immune system that protects against certain bacteria, parasites and enveloped viruses. ${ }^{14}$ In addition, blood antigens are considered to be receptors for immune and inflammation responses, which means that a biological association between $\mathrm{ABO}$ blood groups and HBV infection, for example, probably exists. ${ }^{15,16}$ Consequently, recent reports have suggested that $\mathrm{ABO}$ blood groups might play a role in COVID-19 infection. ${ }^{1,17,18}$

Furthermore, the association of particular blood groups with increased risk of COVID-19 infection is still controversial. Therefore, this retrospective cohort study aimed to study the distribution characteristics of $\mathrm{ABO}$ and RhD blood groups for COVID-19 susceptibility and outcomes through different nationalities in Makkah city with known $\mathrm{ABO}$ and $\mathrm{RhD}$ blood groups.

Methods. A retrospective cohort study was carried out in different hospitals (Alnoor Specialist Hospital, Hera General Hospital, Ajyad Hospital, East Arafat Hospital, and King Faisal Hospital) in Makkah, Saudi Arabia, between November 2020 and June 2021. We assessed 2617 patients, distributed as five different ethnic groups Saudi, Arabs (Egyptians, Yamani, Sudanese, Syrian), South Asian (Myanmar, Bangladesh, Pakistan, Indian, Afghanistan), Southeast Asian (Indonesia, Philippines, Malaysia), and African (Ethiopia, Nigeria, Niger, Mali). The inclusion criteria were for all patients who aged 18 years and above with registered $\mathrm{ABO}$ and $\mathrm{RhD}$ blood group who were diagnosed with COVID-19 with a positive real-time reverse transcriptase polymerase chain-reaction test (RT-PCR) of SARS-CoV-2 on nasal or pharyngeal swab samples. However, patients who were aged under 18 years, pregnant women, those who did not have registered $\mathrm{ABO}$ and $\mathrm{Rh}$ blood 
groups and those not diagnosed with COVID-19 were excluded from the study. Data documented from patient's files included gender, nationality, age, $\mathrm{ABO}$ and $\mathrm{Rh}$ blood group, and patient's outcomes: either they improved or died. The latest surveys of $\mathrm{ABO}$ blood group distribution using 5000 blood donation samples collected at Al-Noor Specialist Hospital in Makkah city were used as reference controls. ${ }^{18}$

The data quality was carefully examined in these hospitals by health care practitioners and the authors before review. This study was approved by the Institutional Review Board of Ministry of Health $(\mathrm{MOH})$, Makkah, and Umm Al-Qura University, Saudi Arabia, (approval number: HAPO-02K-012-2020-08431).

Statistical analysis. The Statistical Package for Social Sciences, version 20 (IBM Inc., Chicago, IL, USA) was applied for all statistical analyses. Continuous (numerical) data are represented by the mean standard deviation, while categorical (discrete) data are represented by numbers (percentages). The student's t-test and the Mann-Whitney $U$ test were used to assess if there were statistically meaningful variations between classes. GraphPad Prism 8 for Pearson's Chi-squared tests correlation to measure correlation coefficients. Also, relative risk (RR) with 95\% CIs for specific blood types in COVID-19 patients were assessed with logistic regression models. $P<0.05$ was considered statistically significant.

Results. A cohort of 4609 positive cases of COVID-19 from different hospitals in Makkah city during the period between November 2020 and June 2021 were assayed. A total of 2617 patients with sufficient information on their $\mathrm{ABO}$ and $\mathrm{RhD}$ blood groups were included; and 1992 cases were excluded from the study due to insufficient data on $\mathrm{ABO}$ and $\mathrm{RhD}$ blood groups. Table 1 shows the demographic and clinical characteristics of COVID-19 patients; the percentage of males in the COVID-19 population analyzed here was $66.8 \%$, with $33.2 \%$ females $(p<0.0001)$. According to age group, 801 were $\leq 40$ years old $(30.6 \%), 1197$ were $41-56$ years old $(45.7 \%)$, and 619 were $>60$ years old $(23.7 \%)$. The median age of the population was 49 , and the most infected age group in this population was 41 to 56 -year-olds.

Among COVID-19 patients, a total of 2106 cases improved, a total of 77 all-cause deaths occurred during hospitalization, and the remaining 434 cases were transferred to other hospitals, with no sufficient data on the prognosis and outcome. Out of those who improved and died groups, the percentage of males was
Table 1 - Demographic characteristics and ethnicity of the study population.

\begin{tabular}{|c|c|c|c|c|c|c|}
\hline \multirow[t]{2}{*}{ Variables } & \multicolumn{2}{|c|}{$\begin{array}{c}\text { Total } \\
(\mathbf{n}=2617)\end{array}$} & \multicolumn{2}{|c|}{$\begin{array}{l}\text { Improve } \\
(\mathrm{n}=2106)\end{array}$} & \multicolumn{2}{|c|}{$\begin{array}{l}{ }^{*} \text { Died } \\
(77)\end{array}$} \\
\hline & $\mathrm{n}$ & $\%$ & $\mathrm{n}$ & $\%$ & $\mathrm{n}$ & $\%$ \\
\hline \multicolumn{7}{|l|}{ Gender } \\
\hline Male & 1748 & 66.8 & 1431 & 67.9 & 49 & 63.6 \\
\hline Female & 869 & 33.2 & 675 & 32.1 & 28 & 36.4 \\
\hline$P$-value & 0.0001 & & \multicolumn{4}{|c|}{0.43} \\
\hline \multicolumn{7}{|l|}{ Age } \\
\hline$\leq 40$ & 801 & 30.6 & 652 & 31.0 & 8 & 10.4 \\
\hline $41-59$ & 1197 & 45.7 & 968 & 46.0 & 33 & 42.9 \\
\hline$>60$ & 619 & 23.7 & 486 & 23.0 & 36 & 46.8 \\
\hline$P$-value & 0.0001 & & \multicolumn{4}{|c|}{0.001} \\
\hline \multicolumn{7}{|l|}{ Nationality } \\
\hline${ }^{\#}$ Saudi & 953 & 36.4 & 731 & $34.7^{\dagger}$ & 34 & 44.2 \\
\hline Arabic & 464 & 17.7 & 382 & $18.1^{\dagger}$ & 5 & 6.5 \\
\hline "South Asia & 1064 & 40.7 & 879 & $41.7^{\dagger}$ & 33 & 42.9 \\
\hline $\begin{array}{l}\text { Southeast } \\
\text { Asia }\end{array}$ & 64 & 2.4 & 54 & 2.6 & 1 & 1.3 \\
\hline Africa & 72 & 2.8 & 60 & 2.8 & 4 & 5.2 \\
\hline${ }^{*} P$-value & 0.04 & & & 0.03 & & \\
\hline
\end{tabular}

higher than females $(p=0.43)$. Pearson's Chi-squared tests revealed a significant difference between the distribution of individuals in the diverse age groups in both improved and died groups $(p<0.001)$, as shown in (Table 1).

Saudi Arabia is a multiethnic nation; therefore, this study included 5 ethnic groups (Saudi, Arabs, South Asian, Southeast Asian and African). Among the COVID-19 patients, there were 953 Saudis, 1064 South Asians, 464 Arabs, 64 Southeast Asians and 72 Africans. South Asian constituted the majority of the cohort (40.7\%). South Asians had higher odds of COVID-19 infection when compared to Saudis $(\mathrm{OR}=1.12,95 \% \mathrm{CI}: 1.074$ to $1.24, p<0.04)$. Improved cases were predominant in both Saudi and Arabic ethnic groups (52.8\%; constituting $34.7 \%$ and $18.1 \%$, respectively) compared to Southeast Asians (41.7\%) $(p<0.0001)$. No significant differences were reported in the mortality rate: in the Saudi and Arabic groups, it was $44.2 \%$ and $6.5 \%$, respectively, whereas it reached $42.9 \%$ in South Asians ( $p=0.5)$. On the other hand, the ethnicities least infected with COVID-19 were found to be Southeast Asian and African populations (2.4\% and 2.8, respectively), as shown in Table 1.

Comparison of the $A B O$ blood group distribution of 2617 patients with COVID-19. The ABO blood group distribution of 2617 patients with COVID-19 revealed that there were $890(34.00 \%)$ type $\mathrm{O}$ patients $(\mathrm{O}+=780$; 
O- =110), $724(27.70 \%)$ type A patients $(\mathrm{A}+=620$; A$=104), 624(23.84 \%)$ type $\mathrm{B}$ patients $(\mathrm{B}+=474$; $\mathrm{B}-=$ $150)$ and $379(14.48 \%)$ type $A B$ patients $(A B+=297$; $A B-=82$ ). Blood type $O$ was the most prevalent blood type in the reference population, whereas type $A B$ was the least prevalent (Table 2). Type $\mathrm{O}+$ and $\mathrm{A}+$ blood were more frequent in the COVID-19 patient group, whereas type $\mathrm{AB}$ - was the least common. (Table 2). The COVID-19 patient group contained higher percentages of individuals with type $\mathrm{O}+$ and $\mathrm{A}+$ blood, with type $\mathrm{AB}$ - the least common type (Table 2). There is evidence for an association between blood group and COVID-19 infection among the study population $(p<0.001)$.

The proportion of COVID-19 patients with type A blood was not significantly greater than the proportion of the reference population $(27.7 \%$ vs. $28.3 \%, p=0.6)$; conversely, the proportion of COVID-19 patients with type $\mathrm{B}$ and $\mathrm{AB}$ blood was significantly higher than the proportion of the reference population $(23.8 \%$ vs. $19.3 \% ; 14.5 \%$ vs. $4.5 \%$, respectively, $p=0.0001$ ), whereas the proportion of COVID-19 patients with type $\mathrm{O}$ blood was significantly lower than the proportion of reference population ( $34 \%$ vs. $47.9 \%, p=0.0001$ ), as shown in Figure 1.

Patients with non-O $(\mathrm{A}, \mathrm{B}$, and $\mathrm{AB})$ blood types had a greater risk of contracting COVID-19 than those with $\mathrm{O}$ blood type $(\mathrm{RR}=1.16,95 \% \mathrm{CI}=1.107-1.218$, $p=0.0001$ ), whereas blood group $\mathrm{O}$ patients had a lower risk of contracting COVID-19 than patients with other blood types $(\mathrm{RR}=0.783,95 \% \mathrm{CI}=0.733-0.836$, $p=0.0001)$. Notably, our results also showed that those with blood group $\mathrm{AB}$ have an increased risk of infection $(\mathrm{RR}=3.23,95 \% \mathrm{CI}=2.702-3.821, p=0.0001)$ compared with other $\mathrm{ABO}$ blood groups. A blood group (RR, $0.977,95 \%$ CI $0.883-1.082, p=0.6$ ) and B blood group $(\mathrm{RR}=1.24,95 \%$ CI 1.124-1.382, $p=0.0001)$ seemed to have a trend of higher risk for COVID-19 infection, suggesting that blood type $\mathrm{O}$ is the least susceptible to COVID-19, whereas those subjects with other blood group types, $\mathrm{B}, \mathrm{AB}$, and $\mathrm{A}$, are most at risk, as shown in Table 2. In contrast, A-, AB-, B- and O- blood types

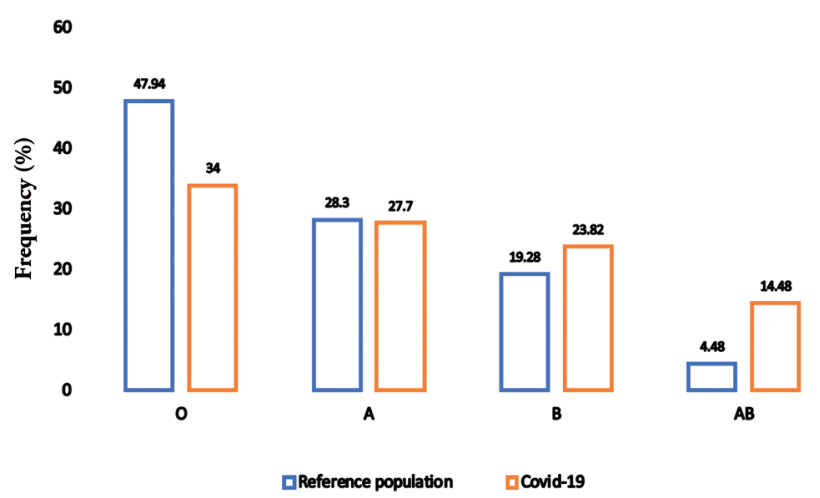

Figure 1 - Proportion $\mathrm{ABO}$ blood type with reference population among COVID-19 infection; no significant with blood type A $(p=0.6)$, high significance with blood type B and $\mathrm{AB}(p=0.0001)$ and lower significantly with blood type $\mathrm{O}$ $(p=0.0001)$.

Table 2 - Distribution and risk of the ABO blood group in 2617 patients with COVID-19 (N=2617).

\begin{tabular}{|c|c|c|c|c|c|c|c|c|c|c|}
\hline & \multicolumn{6}{|c|}{ Rh positive (2171) } & \multicolumn{4}{|c|}{ Rh negative (446) } \\
\hline & \multicolumn{2}{|c|}{$\begin{array}{c}\text { A } \\
724(27.7)\end{array}$} & \multicolumn{2}{|c|}{$\begin{array}{c}\text { B } \\
624(23.8)\end{array}$} & \multicolumn{2}{|c|}{$\begin{array}{c}\mathrm{AB} \\
379(14.5)\end{array}$} & \multicolumn{2}{|c|}{$\begin{array}{c}{ }^{\dagger} \text { non-O } \\
1727(66.0)\end{array}$} & \multicolumn{2}{|c|}{$\begin{array}{c}\mathrm{O} \\
890(34.0)\end{array}$} \\
\hline & $A+$ & A- & $\mathrm{B}+$ & B- & $\mathrm{AB}+$ & $\mathrm{AB}-$ & + & - & $\mathrm{O}+$ & O- \\
\hline \multicolumn{11}{|c|}{${ }^{*}$ Reference population (Makkah area) } \\
\hline 5000 & $1314(26.3)$ & $101(2.0)$ & $883(17.66)$ & $81(1.6)$ & $216(4.3)$ & $8(0.2)$ & $2413(48.3)$ & $190(3.8)$ & $2190(43.8)$ & $207(4.1)$ \\
\hline \multicolumn{11}{|l|}{ Patients } \\
\hline 2617 & 620 & 104 & 474 & 150 & 297 & 82 & 1391 & 336 & 780 & 110 \\
\hline $\mathrm{RR}$ & \multicolumn{2}{|c|}{0.977} & \multicolumn{2}{|c|}{1.24} & \multicolumn{2}{|c|}{3.23} & \multicolumn{2}{|c|}{1.16} & \multicolumn{2}{|c|}{0.783} \\
\hline $95 \% \mathrm{CI}$ & \multicolumn{2}{|c|}{$0.883-1.082$} & \multicolumn{2}{|c|}{$1.124-1.382$} & \multicolumn{2}{|c|}{$2.702-3.821$} & \multicolumn{2}{|c|}{$1.107-1.218$} & \multicolumn{2}{|c|}{$0.733-0.836$} \\
\hline$P$-value & \multicolumn{2}{|c|}{0.6} & \multicolumn{2}{|c|}{0.0001} & \multicolumn{2}{|c|}{0.0001} & \multicolumn{2}{|c|}{0.0001} & \multicolumn{2}{|c|}{0.0001} \\
\hline Died & \multicolumn{6}{|c|}{ Rh positive (58) } & \multicolumn{4}{|c|}{ Rh negative (19) } \\
\hline 77 & 16 & 5 & 10 & 8 & 11 & 2 & --- & --- & 21 & 4 \\
\hline $\mathrm{RR}$ & \multicolumn{2}{|c|}{0.988} & \multicolumn{2}{|c|}{0.984} & \multicolumn{2}{|c|}{1.14} & & & \multicolumn{2}{|c|}{0.965} \\
\hline $95 \% \mathrm{CI}$ & \multicolumn{2}{|c|}{$0.673-1.452$} & \multicolumn{2}{|c|}{$0.645-1.501$} & \multicolumn{2}{|c|}{$0.684-1.904$} & & & \multicolumn{2}{|c|}{$0.683-1.304$} \\
\hline$P$-value & \multicolumn{2}{|c|}{0.9} & \multicolumn{2}{|c|}{0.9} & 0 . & & & & 0. & \\
\hline
\end{tabular}


have shown increased susceptibility to COVID-19 compared to the reference control population ( $p=0.001)$. Exploring this association further demonstrates that the risk of contracting COVID-19 is higher among $446 \mathrm{RhD}$-negative patients $(\mathrm{RR}=1.99,95 \% \mathrm{CI}=1.755$ 2.265, $p=0.0001)$ compared to the $2171 \mathrm{RhD}$-positive patients $(\mathrm{RR}=0.945,95 \% \mathrm{C}=0.910-0.981, p=0.003)$.

The proportions of blood groups $\mathrm{O}, \mathrm{A}, \mathrm{B}$ and $\mathrm{AB}$ in the 77 dead patients were $32.46 \%, 27.3 \%, 23.4 \%$ and $16.88 \%$, respectively. Among ABO blood groups, type $\mathrm{O}$ was the most common, and type $\mathrm{AB}$ was the least common. The dead COVID-19 patients contained higher reference population percentages of individuals with type $\mathrm{O}+$ and $\mathrm{A}+$ blood; type $\mathrm{AB}$ - was the least common type (Table 2). These results corresponded to not significantly associated with a risk of death compared with blood groups $\mathrm{O}, \mathrm{A}, \mathrm{B}$ and $\mathrm{AB}$ ( $p=0.8$, 0.9, 0.9 and 0.6, respectively (Table 2).

Association between ABO Blood Groups with different ethnicities among COVID-19 Infection. Makkah is the Islamic world's holiest capital city; thus, multiethnic inhabitants represent a sizable community. Similarities was demonstrated in the frequency rankings of $\mathrm{ABO}$ and $\mathrm{Rh}$ blood groups among Saudi and non-Saudi reference populations. ${ }^{17}$ The ABO blood group distributions of 953 Saudis, 1064 South Asians, 464 Arabs, 64 Southeast Asians, and 72 Africans with COVID-19 are shown in Figure 2 and Table 3. We reanalyzed and found an adjusted $\mathrm{ABO}$ group distribution which was very similar to our initial result. Due to economic reasons, a significant number of South Asian expatriates are living in Saudi Arabia. This population comprised a large proportion in this study, which enabled comparisons between them and the Saudi population rather than another small ethnic population. These results corresponded to a significantly increased risk of non-O blood group $(A, B$ and $A B)$ for COVID-19 with Saudi (RR=1.17, 95\% CI=1.0921.266, $p=0.0001)$ and South Asian patients $(\mathrm{RR}=1.12$, 95\% CI $=1.043-1.212, p=0.002)$ and decreased risk of blood group O for COVID-19 with Saudi $(\mathrm{RR}=0.787$, 95\% CI $=0.715-0.869, p=0.0001)$ and South Asian patients $(\mathrm{RR}=0.798,95 \% \mathrm{CI}=0.716-0.890, p=0.0001)$, as shown in Table 3.

Our results also showed that blood group $\mathrm{AB}$ has an increased risk of infection compared with other $\mathrm{ABO}$ blood groups. On the other hand, other ethnicities (Arab, Southeast Asian, African) also exhibited an increased risk with non-O blood $(\mathrm{A}, \mathrm{B}$, and $\mathrm{AB})$ and decreased risk with blood group $\mathrm{O}$ for COVID-19 infection, as shown in Table 3, which was very similar to our initial result. Finally, there was no difference in the distribution and relative risk (RR) of $A B O$ groups infected with COVID-19 compared with different ethnic groups.

Discussion. On 2 March 2020, MOH reported the first case of coronavirus infection in a resident who had returned from Iran via the Kingdom of Bahrain. At the Saudi port of entry, he did not disclose his condition. As of June 25 2021, 480,702 reported cases in Saudi Arabia and a total of 7743 deaths have been reported by $\mathrm{MOH} .{ }^{17}$ We carried out this study to statistically analyze the distribution characteristics of $\mathrm{ABO}$ and $\mathrm{RhD}$ blood groups for COVID-19 susceptibility and outcomes through a retrospective cohort analysis of

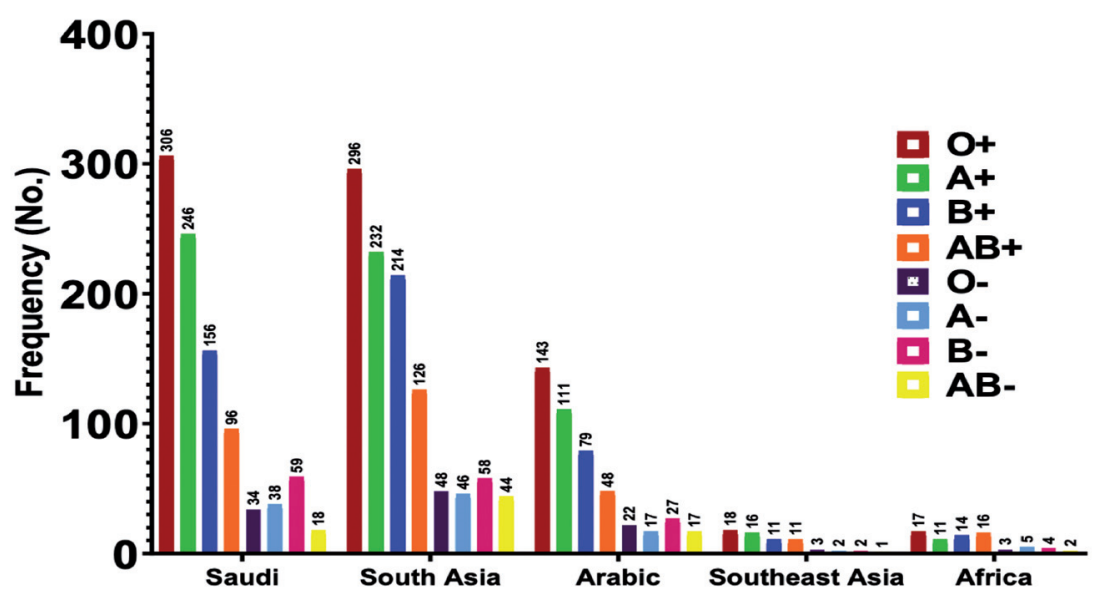

Figure 2 - Distribution of ABO in the 5 different ethnic groups with COVID-19 
Table 3 - Risk of blood types A, B, and O in the 5 different ethinic groups with COVID-19.

\begin{tabular}{|c|c|c|c|c|c|}
\hline Ethnic groups & A & $\mathrm{B}$ & $\mathrm{AB}$ & ${ }^{\dagger}$ Non-O & $\mathrm{O}$ \\
\hline \multicolumn{6}{|c|}{ Reference population (Saudi) } \\
\hline 3196 & $911(28.5 \%)$ & $547(17.1 \%)$ & $136(4.25 \%)$ & 1594 & $1602(50.1 \%)$ \\
\hline \multicolumn{6}{|l|}{ Saudi (patients) } \\
\hline 953 & 284 & 215 & 114 & 613 & 340 \\
\hline $\mathrm{RR}$ & 1.035 & 1.25 & 2.617 & 1.176 & 0.787 \\
\hline $95 \% \mathrm{CI}$ & $0.920-1.163$ & $1.091-1.453$ & $2.060-3.324$ & $1.092-1.266$ & $0.712-0.869$ \\
\hline$P$-value & 0.6 & 0.001 & 0.001 & 0.001 & 0.001 \\
\hline \multicolumn{6}{|c|}{ *Reference population (Non-Saudi) } \\
\hline 1804 & $504(27.9 \%)$ & $417(23.11 \%)$ & $88(4.87 \%)$ & 1009 & $795(44.06 \%)$ \\
\hline \multicolumn{6}{|l|}{ South Asia } \\
\hline 1064 & 278 & 272 & 170 & 720 & 344 \\
\hline $\mathrm{RR}$ & 0.948 & 1.084 & 2.96 & 1.12 & 0.798 \\
\hline $95 \% \mathrm{CI}$ & $0.832-1.080$ & $0.945-1.0243$ & $2.313-3.792$ & $1.093-1.212$ & $0.716-0.890$ \\
\hline$P$-value & 0.4 & 0.2 & 0.001 & 0.002 & 0.001 \\
\hline \multicolumn{6}{|l|}{ Arabic } \\
\hline 464 & 128 & 106 & 65 & 299 & 165 \\
\hline $\mathrm{RR}$ & 0.990 & 0.990 & 2.641 & 1.092 & 0.857 \\
\hline $95 \% \mathrm{CI}$ & $0.833-1.175$ & $0.817-1.201$ & $1.945-3.586$ & $0.987-1.208$ & $0.743-0.989$ \\
\hline$P$-value & 0.9 & 0.9 & 0.001 & 0.08 & 0.03 \\
\hline \multicolumn{6}{|l|}{ Southeast Asia } \\
\hline 64 & 18 & 13 & 12 & 43 & 21 \\
\hline $\mathrm{RR}$ & 1.001 & 0.899 & 3.39 & 1.120 & 0.807 \\
\hline $95 \% \mathrm{CI}$ & $0.663-1.522$ & $0.543-1.487$ & $1.943-5.930$ & $0.884-1.419$ & $0.554-1.175$ \\
\hline$P$-value & 0.9 & 0.6 & 0.001 & 0.3 & 0.2 \\
\hline \multicolumn{6}{|l|}{ Africa } \\
\hline 72 & 16 & 18 & 18 & 52 & 20 \\
\hline $\mathrm{RR}$ & 0.832 & 1.065 & 4.30 & 1.169 & 0.710 \\
\hline $95 \% \mathrm{CI}$ & $0.531-1.305$ & $0.698-1.624$ & $2.712-6.817$ & $0.944-1.446$ & $0.480-1.051$ \\
\hline$P$-value & 0.4 & 0.7 & 0.001 & 0.2 & 0.08 \\
\hline
\end{tabular}

different nationalities in Makkah tested for COVID-19 with known $\mathrm{ABO}$ and $\mathrm{RhD}$ blood groups.

According to our reported data, there was a significant difference between male and female subjects infected with COVID-19, presenting $p<0.0001$. Chen et $\mathrm{al},{ }^{19}$ observed a greater number of men than women in 99 cases of COVID-19 infection. On the other hand, a large meta-analysis identified that males and females are at equivalent risk of infection. At all ages, gender differences in the prevalence and outcomes of infectious diseases exist, with males generally carrying a greater burden of bacterial, viral, fungal and parasitic infections. This may be caused by fundamental differences in immune responses between males and females, likely to have been a driving factor in the COVID-19 pandemic's major gender-bias. ${ }^{20,21}$ With respect to other demographic data such as age, the median age of the population of our study was 49 years old, and the most infected age group in this population were $41-56$ years old. In our study population, a total of 77 cases died and 2106 cases improved, with a significant difference between the distribution of COVID-19-infected patients in diverse age groups in both improved and died patients $(p<0.001)$.

Blood groups $(\mathrm{ABO})$ have a potential role in host susceptibility to infection through differences in blood group antigen expression; these act as receptors or coreceptors for microorganisms, parasites, and viruses. Furthermore, many blood group antigens use membrane microdomains to promote intracellular absorption, signal transduction and cell adhesion. ${ }^{10}$ Blood group antigens have the ability to alter innate immune responses to infection. ${ }^{19}$ Among the reference population blood types for our study, type $\mathrm{O}$ was the most common, and type $\mathrm{AB}$ was the least common. ${ }^{18}$ Regarding the distribution of COVID-19 infection among different $\mathrm{ABO}$ blood groups, the largest proportion of the population infected with COVID-19 was $34 \%$ with type $\mathrm{O}$, followed by $27.70 \%$ with type $\mathrm{A}$, then $23.8 \%$ and $14.5 \%$ with blood groups $B$ and $A B$, 
respectively. The proportion of COVID-19 patients with type A blood was not statistically different from the proportion of the reference population $(p=0.6)$; however, the proportion of COVID-19 patients with type $\mathrm{B}$ and $\mathrm{AB}$ blood was considerably greater than the proportion of the reference population $(p=0.0001)$, whereas the proportion of patients, with COVID-19 with type $\mathrm{O}$ blood was significantly lower than the proportion of the reference population $(p=0.0001)$. A large meta-analysis by Kabrah et al, ${ }^{21}$ demonstrated that COVID-19 infects all ABO blood groups at varying rates. These data also revealed that those with blood groups $\mathrm{A}$ and $\mathrm{O}$ were more likely to be among the COVID-19-infected patients. COVID-19 infection was less common in people with blood group $\mathrm{AB} .{ }^{20}$ Our results are different from those by Jiao et $a{ }^{21}$ who showed that the $\mathrm{ABO}$ blood group distributions of 1775 COVID-19 patients from Wuhan Jinyintan Hospital, China was $37.8 \%$ for types A, $26.4 \%$ for type $\mathrm{B}, 10 \%$ for type $\mathrm{AB}$ and $25.8 \%$ for type O. It is important to note that the features of $\mathrm{ABO}$ blood types vary by area and race. Additionally, this system is often used as a genetic marker in the human genome and has been widely explored in different infectious and non-infectious diseases.

In the current study, we found that $\mathrm{ABO}$ blood groups displayed varying risks of infection from COVID-19; hence, the ABO blood type is a biomarker for differential COVID-19 susceptibility. COVID-19 risk was higher in patients with blood groups $\mathrm{A}, \mathrm{B}$, and $\mathrm{AB}$ than in those with blood group $\mathrm{O}(\mathrm{RR}=1.16,95 \%$ $\mathrm{CI}=1.107-1.218, p=0.0001$ ), whereas patients with blood group O had a lower risk of COVID-19 than patients with other blood group types $(\mathrm{RR}=0.783,95 \%$ $\mathrm{CI}=0.733-0.836, p=0.0001)$. Notably, our results also showed that blood group $\mathrm{AB}$ exhibited an increased risk of infection $(\mathrm{RR}=3.23,95 \% \mathrm{CI}=2.702-3.821$, $p=0.0001)$, compared with other ABO blood groups: A blood group (RR, 0.977, 95\% CI 0.883-1.082, $p=0.6$ ) and $\mathrm{B}$ blood group $(\mathrm{RR}=1.24$, 95\% CI 1.124-1.382, $p=0.0001)$ seemed to have a trend of higher risk for COVID-19 infection, suggesting that those with an $\mathrm{O}$ blood type are the least susceptible to COVID-19 when compared with reference population, whereas subjects with other blood group types $\mathrm{B}, \mathrm{AB}$, and $\mathrm{A}$ are most at risk. Wu et al, ${ }^{23}$ found that patients with blood group $\mathrm{A}$ had a higher risk of COVID-19 infection, whereas those with blood group $\mathrm{O}$ had a lower risk, implying that the ABO blood group was linked to COVID-19 susceptibility. This is consistent with our findings, suggesting that those with non-O blood groups $(\mathrm{A}, \mathrm{B}$, and $A B)$ may be more susceptible to viral infection.
Another study by Jiao et $\mathrm{al},{ }^{22}$ revealed that $\mathrm{ABO}$ blood groups had varying risks of infection from COVID-19. Specifically, blood group A was linked to a higher risk, whereas blood group $\mathrm{O}$ was linked to a lower risk. ${ }^{22}$ These findings are consistent with previous studies, which found that $\mathrm{ABO}$ blood groups have a similar risk of infection with other coronaviruses. Mahmoud et $\mathrm{al},{ }^{24}$ found that individuals with $\mathrm{O}$ blood type had a reduced susceptibility to SARS infection in the Hong Kong population.

In previous studies, the $\mathrm{ABO}$ blood group distribution also contributed to significant differences in other viral infections. Kaidarova et $\mathrm{al},{ }^{25}$ discovered that individuals with A blood groups are more likely to develop severe disease outcomes following West Nile virus infection, due to genetic susceptibility. ${ }^{25,26}$ Norovirus genetic susceptibility is largely determined by the presence of histo-blood group antigens (HBGAs), specifically those associated with the ABO, secretor and Lewis phenotypes. ${ }^{27}$ According to Guillon et $\mathrm{al},{ }^{28}$ natural human anti-A antibodies may block the interaction between COVID-19 and its receptor; this is a hypothesized theory of anti-A antibodies specifically blocking COVID-19 S protein-expressing cells' adherence to ACE2-expressing cell lines. The similarity in nucleic acid sequences and ACE2 receptor binding between SARS-CoV and COVID-19, which provides protection, could explain why people with blood group A are more susceptible to SARS-CoV infection than people with blood group $\mathrm{O}$, and it is possible that the decreased COVID-19 vulnerability of individuals with blood group $\mathrm{O}$ and the greater susceptibility of individuals with blood group A could be explained by the presence of natural anti-blood group antibodies in the blood, specifically the anti-A antibody. ${ }^{29,30,31}$ Other mechanisms, however, may require further investigation. ${ }^{32}$

In our study, the $\mathrm{RhD}$-negative group compared to the reference population of A-, AB-, B- and O- blood groups exhibited increased susceptibility to COVID-19. Furthermore, this association revealed that the risk of contracting COVID-19 was significantly higher in $\mathrm{RhD}$ - patients than in $\mathrm{RhD}+$ patients $(p=0.0001)$. Different recent studies support our results; the main findings by Saify et $\mathrm{al}^{32}$ were that there is a strong correlation between the Rh- blood group and the risk of developing COVID-19. Our findings are similar with the findings of a recent ecological study. ${ }^{32}$ The authors reported that the frequency of the Rh- blood group is positively associated with the prevalence, mortality, and case fatality of COVID-19, based on data from 86 countries. This means that COVID-19 
is more prevalent in countries where the $\mathrm{Rh}$ blood group is more prevalent. ${ }^{33,34}$ Meanwhile, Haunstrup et $a l,{ }^{34}$ decided that there were no differences between positively tested cases and a reference population in the $\mathrm{RhD}$ group. According to a study by Ray et $\mathrm{al},{ }^{35}$ which was conducted in a universal health care system with widespread SARS-CoV-2 testing, $\mathrm{O}$ and Rh- blood groups were associated with a slightly lower risk of SARS-CoV-2 infection, as well as severe COVID-19 illness or death. ${ }^{35,36}$ In our study, there was higher prevalence percentage among death groups in patients with blood group $\mathrm{O}$, specifically $\mathrm{O}_{+}$, which is consistent with the result reported by Rey et al. ${ }^{35}$ Contrary to our results, O blood group was associated with a lower risk of death compared with non-O blood groups, as reported by Jiao et al. ${ }^{22}$

Saudi Arabia is referred to as the "heart" of the Arab and Islamic worlds; additionally, Saudi Arabia is among the top five destination countries for economic immigrants around the world, which means that multiple ethnic groups are resident in the Kingdom. In our study, we analyzed COVID-19 patients, which included 953 Saudis, 1064 South Asians, 464 Arabs, 64 Southeast Asians and 72 Africans. With the vast majority of cases from South Asia (40.7\%), higher odds of COVID-19 infection were exhibited when compared to Saudi cases (OR=1.12, 95\% CI: 1.074 to 1.24, $p<0.04)$. Ali et al, ${ }^{37}$ determined that South Asians were more likely than Arabs to acquire a severe form of COVID-19 infection, which was associated with a higher death rate. Ethnicity has been identified as a potential risk factor for poor COVID-19 prognosis and outcome. Numerous explanations exist for why South Asian ethnicity groups may have higher rates of SARS-CoV-2 infection. Contact tracing studies have shown that the majority of new infections are caused by close sustained contact with someone infected with SARS-CoV-2. SARS-CoV-2 spreads much more rapidly in enclosed and congested environments. ${ }^{38}$

Individuals from South Asia are more likely to live in extended families with several generations. ${ }^{39}$ They are also more likely to be a lower socioeconomic level, which increases their chance of living in overcrowded homes or dwellings with shared facilities or communal areas. Furthermore, ethnic minorities are more likely to be employed as critical workers or to be unable to work from home; therefore, they maintain contact with others through work or commuting. ${ }^{40-42}$

Regarding associations between the risk of COVID-19 and multiethnicity in Makkah city, which is considered as the Islamic world's holiest capital city, the results showed significantly increased risk of COVID-19 infection in those with non-O blood groups (A, B and AB) in Saudi $(R R=1.17,95 \% C I=1.092-$ 1.266, $p=0.0001)$ and South Asian patients $(R R=1.12$, $95 \% \mathrm{CI}=1.043-1.212, p=0.002)$, and decreased risk of COVID-19 infection in those with an O blood group in Saudi ( $\mathrm{RR}=0.787,95 \% \mathrm{CI}=0.715-0.869$, $p=0.0001)$ and South Asian patients ( $\mathrm{RR}=0.798,95 \%$ $\mathrm{CI}=0.716-0.890, p=0.0001)$. AB blood group patients have an increased risk of infection compared with other ABO blood groups. However, other ethnicities (Arab, Southeast Asian, African) also exhibited an increased risk of COVID-19 infection in non-O blood groups (A, $\mathrm{B}$ and $\mathrm{AB}$ ) and decreased risk in $\mathrm{O}$ blood groups. These differences may contribute to the fact that study regions, races, sample sizes, and the proportions of COVID-19 positive participants who participate vary according to their $\mathrm{ABO}$ blood group. There are clear significant differences between cases which improved in Saudi and Arabic groups and Southeast Asian patients $(p<0.0001)$. People from certain ethnicities are more prone to severe outcomes. Socioeconomic status, appropriate medical care, and a greater burden of other diseases may all play a role in global disparities in mortality rates. ${ }^{40}$

Study limitations. The sample size was limited. We did not include large scale population due to missed data regarding $\mathrm{ABO}$ blood types and other demographic data. Other limitation is that the study was confined to Makkah region only.

In conclusion, the current study provides evidence guide regarding COVID-19 infection, $\mathrm{ABO}$ blood group vulnerabilities to COVID-19 and ethnicity as this study emphasize that the link between blood types (ABO and $\mathrm{RhD}$ ) and COVID-19 is likely to be influenced by a variety of factors, including (but not limited to) ethnicity and $\mathrm{RhD}$ blood group, with no proportional differences among the different ethnicityrelated blood groups in contracting COVID-19 infection. People with $\mathrm{O}$ blood groups are more likely to contract COVID-19 than those with other blood groups. Specifically, individuals with type $\mathrm{O}+$ and A+ blood presented larger percentages, whereas type $\mathrm{AB}$ - was the least common. The risk of contracting COVID-19 risk was higher in patients with non-O blood groups (A, B, and $\mathrm{AB}$ ) than in those with blood group $\mathrm{O}$, and was significantly higher in $\mathrm{RhD}$ - than in $\mathrm{RhD}+$ patients.

It is highly recommended that public health intervention programs should focus on increasing the perception of the benefits of COVID-19 vaccination among those with blood group $\mathrm{O}$ who are more likely to contract COVID-19 than other blood 
groups, such as those with non-O blood groups (A, $\mathrm{B}$, and $\mathrm{AB}$ ) due to higher COVID-19 risk and those with low socioeconomic status due to their higher odds of contracting COVID-19 infection than other populations.

Acknowledgment. We want to thank the 4th and 6 th year medical students from the College of Medicine, Umm Al Qurra University, Makkah, Saudi Arabia who participated as data collector in the study; Aali Marzouq alhuzali, Hussam Saud Aloufi, Eyyad Adeeb Edrees, Hussam Abdulaziz Albarakati, Walaa Abdu Ahmed, Ghada Mohammed Alshahrani, Ameerah Sami Mandourah, Sara Bandar Badirah, Orjwan Ebrahem Alhajaili, Dhiyaa Jawad Ali Alqasim and Fayrouz Rajab Khateeb. We would also thank Faten Awad Alhadrami Lab Specialist for her work as data collector in the study. We also would like to thank MDPI editing company (https://www. mdpi.com/authors/ english\#English_Editing_Services) for English language editing.

\section{References}

1. Padhi S, Suvankar S, Dash D, Panda VK, Pati A, Panigrahi J, et al. ABO blood group system is associated with COVID-19 mortality: An epidemiological investigation in the Indian population. Transfus Clin Biol 2020; 27: 253-258.

2. World health organization.WHO Director-General's opening remarks at the media briefing on COVID19. [Updated 2020 October 23; Accessed 2021 May 10]. Available from: https:// www.who.int/director-general/speeches/detail/who-directorgeneral-s-opening-remarks-at-the-media-briefing-on-covid-19--23-october-2020

3. World Health Organization. COVID-19 Coronavirus Pandemic; Worldmeter (cumulative \& daily reports). [Updated 2022; 2022 January 24] Available from: https:// www. worldometers.info/coronavirus/\#countries

4. Alyami HS, Naser AY, Dahmash EZ, Alyami MH, Alyami MS. Depression and anxiety during the COVID-19 pandemic in Saudi Arabia: A cross-sectional study. Int J Clin Pract 2021; 75: e14244.

5. Ahn DG, Shin HJ, Kim MH, Lee S, Kim HS, Myoung J, et al. Current status of epidemiology, diagnosis, therapeutics, and vaccines for novel coronavirus disease 2019 (COVID-19). J Microbiol Biotechnol 2020; 30: 313-324.

6. Wenzhong L, Hualan L. COVID-19: Attacks the 1-Beta Chain of Hemoglobin and Captures the Porphyrin to Inhibit Human Heme Metabolism. ChemRxiv 2020.

7. Zhang JJ, Dong X, Cao YY, Yuan YD, Yang YB, Yan YQ, et al. Clinical characteristics of 140 patients infected with SARS-CoV-2 in Wuhan, China. Allergy 2020; 75: 1730-1741.

8. Malik YA. Properties of coronavirus and SARS-CoV-2. Malays J Pathol 2020; 42: 3-11.

9. Anstee DJ. The relationship between blood groups and disease. Blood 2010; 115: 4635-4643.

10. Zhao J, Yang Y, Huang H, Li D, Gu D, Lu X, et al. Relationship between the ABO blood group and the coronavirus disease 2019 (COVID-19) Susceptibility. Clin Infect Dis 2021; 73: 328-331.

11. Rakebrandt $\mathrm{N}$, Joller $\mathrm{N}$. Infection history determines susceptibility to unrelated diseases. Bioessays 2019; 41: e1800191.
12. Fazeli A, Sharifi S, Mohammadi S, Bahraini M, Arabkhazaeli A, Jelveh N, et al. The demographic and serological characteristics of COVID-19 convalescent plasma donors: Identification of basic criteria for optimal donor selection. Transfus Apher Sci 2021; 29: 103302.

13. Yanardag Acik D, Bankir M. Relationship of SARS-CoV-2 Pandemic with Blood Groups. Transfus Med Hemother 2021; 48: 161-167.

14. Jing SW, Xu Q, Zhang XY, Jing ZH, Zhao ZJ, Zhang RH, et al. Are people with blood group o more susceptible to nasopharyngeal carcinoma and have worse survival rates? A systematic review and meta-analysis. Front Oncol 2021; 11: 698113.

15. Jing W, Zhao S, Liu J, Liu M. ABO blood groups and hepatitis $\mathrm{B}$ virus infection: a systematic review and meta-analysis. $B M J$ Open 2020; 10: e034114.

16. Wu BB, Gu DZ, Yu JN, Yang J, Shen WQ. Association between $\mathrm{ABO}$ blood groups and COVID-19 infection, severity and demise: A systematic review and meta-analysis. Infect Genet Evol 2020; 84: 104485.

17. Ministry of Health. MOH Reports First Case of Coronavirus Infection. [Updated 2020 March 02; Accessed 2021 May 10]. Available from: https:/www.moh.gov.sa/en/Ministry/ MediaCenter/News/Pages/News-2020-03-02-002.aspx

18. Ammar Khojah, Talal Qadah. ABO and rhesus blood groups distribution in healthy individuals: an update cross sectional study from Tertiary Care Center in Makkah City, Saudi Arabia. J Res Med Dent Sci 2021; 9: 1-6.

19. Chen N, Zhou M, Dong X, Qu J, Gong F, Han Y, et al. Epidemiological and clinical characteristics of 99 cases of 2019 novel coronavirus pneumonia in Wuhan, China: a descriptive study. Lancet 2020; 395: 507-513.

20. Hoiland RL, Fergusson NA, Mitra AR, Griesdale DEG, Devine DV, Stukas S, et al. The association of $\mathrm{ABO}$ blood group with indices of disease severity and multiorgan dysfunction in COVID-19. Blood Adv 2020; 4: 4981-4989.

21. Kabrah SM, Kabrah AM, Flemban AF, Abuzerr S. Systematic review and meta-analysis of the susceptibility of $\mathrm{ABO}$ blood group to COVID-19 infection. Transfus Apher Sci 2021; 60: 103169.

22. Jiao Z, Yan Y, Hanping H, Dong L, Dongfeng G, Xiangfeng L, et al. Relationship between the ABO Blood Group and the COVID-19 Susceptibility. Clin Infect Dis 2021; 73: 328-331.

23. Wu Y, Feng Z, Li P, Yu Q. Relationship between ABO blood group distribution and clinical characteristics in patients with COVID-19. Clin Chim Acta 2020; 509: 220-223.

24. Mahmoud MH, Alghamdi FA, Alghamdi GA, Alkhotani LA, Alrehaili MA, El-Deeb DK. Study of Post-COVID-19 Syndrome in Saudi Arabia. Cureus 2021; 13: e17787.

25. Kaidarova Z, Bravo MD, Kamel HT, Custer BS, Busch MP, Lanteri MC. Blood group A and Rh(D) negativity are associated with symptomatic West Nile virus infection. Transfusion 2016; 56: 1699-1706.

26. Sharma S, Hagbom M, Carlsson B, Nederby Öhd J, Insulander $\mathrm{M}$, Eriksson R, et al. Secretor status is associated with susceptibility to disease in a large GII.6 norovirus foodborne outbreak. Food Environ Virol 2020; 12: 28-34.

27. Nordgren J, Svensson L. Genetic Susceptibility to Human Norovirus Infection: An Update. Viruses 2019; 11: 226.

28. Guillon P, Clément M, Sébille V, et al. Inhibition of the interaction between the SARS-CoV spike protein and its cellular receptor by anti-histo-blood group antibodies. Glycobiology 
2008; 18: 1085-1093.

29. Lu R, Zhao X, Li J, Niu P, Yang B, Wu H, et al. Genomic characterization and epidemiology of 2019 novel coronavirus: implications for virus origins and receptor binding. Lancet 2020; 395: 565-574.

30. Wang LL, Yang JW, Xu JF. Severe acute respiratory syndrome coronavirus 2 causes lung inflammation and injury. Clin Microbiol Infect 2021; S1198-743X(21)00674-1.

31. Hoffmann M, Kleine-Weber H, Krüger N, Müller M, Drosten C, Pöhlmann S. The novel coronavirus 2019 (2019-nCoV) uses the SARS-coronavirus receptor ACE2 and the cellular protease TMPRSS2 for entry into target cells. bioRxiv 2020; 1-5.

32. Saify K, Alborz. M, Saadat M. Susceptibility to the novel coronavirus disease (COVID-19) is associated with $\mathrm{ABO}$ and Rh blood groups: a case-control study from Afghanistan. Egypt J Med Hum Genet 2021; 22: 1.

33. Ansari-Lari M, Saadat M. The morbidity and mortality of COVID-19 are associated with $\mathrm{ABO}$ and Rh blood groups. Eur J Prev Cardiol 2020: 2047487320939216.

34. Haunstrup TM, Homburg K, Larsen R, Hansen MB, Titlestad $\mathrm{K}$, Aagaard B, et al. Reduced prevalence of SARS-CoV-2 infection in ABO blood group O. Blood Adv 2020; 4: 4990-4993.

35. Ray JG, Schull MJ, Vermeulen MJ, Park AL. Association between $\mathrm{ABO}$ and Rh blood groups and SARS-CoV-2 Infection or Severe COVID-19 Illness : A population-based cohort study. Ann Intern Med 2021; 174: 308-315.

36. Ali H, Alshukry A, Marafie SK, AlRukhayes M, Ali Y, Abbas $\mathrm{MB}$, et al. Outcomes of COVID-19: Disparities by ethnicity. Infect Genet Evol 2021;87: 104639.
37. Martin CA, Jenkins DR, Minhas JS, Gray LJ, Tang J, Williams $\mathrm{C}$ et al. Socio-demographic heterogeneity in the prevalence of COVID-19 during lockdown is associated with ethnicity and household size: Results from an observational cohort study. EClinicalMedicine 2020; 25: 100466.

38. Cevik M, Marcus JL, Buckee C, Smith TC. SARS-CoV-2 transmission dynamics should inform policy. Clin Infect Dis 2021; 73: S170-S176.

39. Asfahan S, Deokar K, Dutt N, Niwas R, Jain P, Agarwal M. Extrapolation of mortality in COVID-19: Exploring the role of age, sex, co-morbidities and health-care related occupation. Monaldi Arch Chest Dis 2020; 90.

40. Jing QL, Liu MJ, Zhang ZB, Fang LQ, Yuan J, Zhang AR, et al. Household secondary attack rate of COVID-19 and associated determinants in Guangzhou, China: a retrospective cohort study. Lancet Infect Dis 2020; 20: 1141-1150.

41. Iacobucci G. Covid-19: deprived areas have the highest death rates in England and Wales. BMJ 2020; 369: m1810.

42. Al-Mulla F, Mohammad A, Al Madhoun A, Haddad D, Ali $\mathrm{H}$, Eaaswarkhanth $\mathrm{M}$, et al. ACE2 and FURIN variants are potential predictors of SARS-CoV-2 outcome: A time to implement precision medicine against COVID-19. Heliyon 2021; 7: e06133. 